READERS' OPINION AND DISCUSSION

OPINION

\section{Further thoughts on the use of the name Leishmania (Leishmania) infantum chagasi for the aetiological agent of American visceral leishmaniasis}

\section{Jeffrey J Shaw}

\author{
Departamento de Parasitologia, Instituto de Ciências \\ Biomédicas, Universidade de São Paulo, Av. Prof Lineu Prestes \\ 1374, 055008-000 São Paulo, SP, Brasil
}

Dear Editor,

I read with great interest the recent discussion (DantasTorres 2006, Lainson \& Rangel 2006) on the name used for the parasite that causes human and canine visceral leishmaniasis in the Americas. Independently I had used (Shaw 2002) the name Leishmania (Leishmania) infantum chagasi for the aetiological agent of American visceral leishmaniasis (AVL) and because of this I wish to add my own comments to this apparent taxonomic dilemma. I whole heartedly agree with Dantas-Torres, Lainson and Rangel that the laws a nomenclature must under all circumstances be obeyed. However, according to the International Code of Zoological Nomenclature (International Commission on Zoological Nomenclature 1999) the name Leishmania (Leishmanina) infantum chagasi is absolutely correct. The question is should the name chagasi be synonymized with infantum? The weight of the published evidence suggests today that at the species level chagasi should be synonymized with infantum. But are we correct in saying that the two parasites are identical? Lainson and Rangel (2006) gave reasons for considering that they are in fact not identical. Molecular biology has shown over and over again that species are composed of genetically distinct groups which are given a status that may or may not fall within the code. Leishmania species are composed of clonal populations whose structure varies according to the characterization method. The challenge that we are facing today is when do we give a name to one of these groups? Clearly if we do then it is advisable to use existing names before creating new ones.

Recent studies on the Old World visceral parasites using the internal transcribed spacer (ITS) (Kuhls et al. 2005) and fluorogenic assays (Quispe-Tintaya et al. 2005) showed consistent genetic diversity and strongly suggest the need for a revision of the group. A logical taxo-

E-mail: jeffreyj@usp.br nomic solution is to create subspecies within the infantum and donovani lineages. But they also emphasized that more than one taxon of visceral parasites occurs in the same geographical area. This is a potential point of considerable confusion since by chance different research groups may or may not examine the same parasites and thus come to conflicting conclusions. Originally there was a tendency to name parasites according to their geographical origin, a practice that in part led to the name L. chagasi. Like this latter species the validity of $L$. archibaldi has been similarly questioned on numerous occasions (Oskam et al. 1998, Jamjoom et al. 2004) but studies using fluorogenic assays (Quispe-Tintaya et al. 2005) have shown that in fact parasites of both $L$. (L.) infantum and $L$. (L.) donovani occur in the Sudan and that name L. archibaldi could be used for Sudanese parasites of the donovani group. What is perhaps initially confusing is that strains labeled as archibaldi occur in both groups but the name was used because of their geographical origin and not specific characters.

It is conceivable that different lineages of infantum may exist in the Americas some being indigenous and others imported. One of the pitfalls of evaluating the validity of a parasite's name is to examine a small number of strains. Only when a larger numbers of isolates from East Africa were examined did it become clear that more than one parasite was present in the region. It is not always easy to plot the geographical expansion of parasites whose reservoirs are man or domestic animals, especially when they do not cause an insidious disease. The Leishmania responsible for visceral leishmaniasis fall within this group and it is probable that present day distributions are the result of both man's migratory movements and enzootics in autochthonous natural reservoirs. In such situations it is essential that adequately large samples are examined from different hosts and environments.

The formulation of names and creating an acceptable classification for any group is an arduous process that may take many years and does not necessarily apply to all the taxa of the group. The general classification that is presently used today for the genus Leishmania (Lainson $\&$ Shaw 1987) was elaborated over a period of approximately 20 years. Previous classifications (Lainson \& Shaw 1979, Lainson 1982, Shaw 1982) used subspecies but it became clear that there were significant differences between the subspecies and so they were abandoned by raising them to the species (Saf'janova 1982, Lainson \&Shaw 1987). This gave room to a system that could cope with the greater levels of diversity indicated by the burgeoning characterization methods. As more data becomes available it appears that in some cases raising subspecies to the species level was correct while in others it is debatable if it was. For instance it is now apparent that $L$. $(L$. amazonensis should not be considered as a subspecies of $L$. (L.) mexicana (Uliana et al. 2000) This brings me to question comments made by Dantas-Torres that in the "current classification of the genus Leishmania there is no subspecies" and that in his view, "L. infantum and $L$. chagasi must be regarded as synonyms, until a new classification of the genus Leishmania is proposed". The 
decision to divide a species into sub-species or raise subspecies to the specific level does not depend on a revision of the genus but on the availability of sufficient data to justify the action. However, it is a matter of opinion as to what differences should be considered as worthy of distinguishing taxa and we must remember that a name should communicate useful and important information. During an on-line discussion on the validity of L. chagasi on Leish-L (present address: Leish-L @lineu.icb.usp.br ) some contributors said that it should be maintained because they immediately knew that the paper dealt with AVL. Taxonomically this opinion is not acceptable but emphasizes that an important function of taxonomy is to transmit information. In relation to this problem DantasTorres (2006) suggest the use of $L$. infantum (=L.chagasi) for "didactic purpose" for AVL parasites. I personally find this confusing and prefer L.(L.).i. chagasi for the Latin American parasites for the reasons that I have given.

In the United States there are well documented cases both imported (Bravo et al. 1993) and autochthonous (Rosypal et al. 2003) canine visceral leishmaniasis but the transmission method of the latter has yet to be determined. In the case of the imported cases and the autochthonous cases it is probably more correct to consider them as being $L$. (L.).i. infantum and not $L$. (L.).i. chagasi. But how does this relate to canine AVL in Latin America? Given the extension of the problem and the differences in epidemiology it reinforces the argument that we are most probably dealing with imported and autochthonous parasites and that until more strains are examined we should not synonomize the name chagasi at all taxonomic levels.

I conclude that because there are still so many unanswered questions surrounding the origin, identity, and epidemiology of the AVL parasites that it is more prudent to continue to use the name $L$. (L.) infantum chagasi. There is also a strong academic argument against completely synonyomizing the name chagasi. If this is done there is a real danger that many potential lines of research will be killed before they are born. One of the last century's most outstanding parasitologists, Professor PCC Garnham, always maintained that it was better to give a name and keep it alive otherwise the parasite in question could be lost for ever. Lainson and Rangel (2006) cited the differences that have been found between a small number of Old World and American visceral Leishmania isolates. There are no constraints on individuals or groups giving names as long as they are based on tangible valid characters that can be used to differentiate them from other members of the same group. It is then up to the scientific community to judge this decision. In the end one of the most significant guides as to the acceptance of a name is if it is consistently used.

In my opinion we are at present witnessing speciation due to natural selection in the vector of the visceral parasites. Differences in sand fly gut wall galectins are responsible for specific parasite adhesion (Kamhawi et al. $2000,2004)$ and consequently successful transmission. Adaptation to new vectors will depend on the compatibility of parasite surface glycolipids with gut wall galectins. It will be interesting to see the level of similarity between the galectins of the principal American vector (Lutzomyia longipalpis) and those of the Old World (Phlebotomus perniciosus, P. ariasi, P. neglectus, and P. perfiliewi).

\section{REFERENCES}

Bravo L, Frank LA, Brenneman KA 1993. Canine leishmaniasis in the United-States. Compend Contin Educ Pract Vet 15: 699-708.

Dantas-Torres F 2006. Leishmania infantum versus Leishmania chagasi: do not forget the laws of nomenclature. Mem Inst Oswaldo Cruz 101: 117-118.

International Commission on Zoological Nomenclature 1999. International Code of Zoological Nomenclature. The International Trust for Zoological Nomenclature, London, 306 pp.

Jamjoom MB, Ashford RW, Bates PA, Chance ML, Kemp SJ, Watts PC, Noyes HA 2004. Leishmania donovani is the only cause of visceral leishmaniasis in East Africa; previous descriptions of $L$. infantum and " $L$. archibaldi" from this region are a consequence of convergent evolution in the isoenzyme data. Parasitology 129: 399-409.

Kamhawi S, Modi GB, Pimenta PF, Rowton E, Sacks DL 2000. The vectorial competence of Phlebotomus sergenti is specific for Leishmania tropica and is controlled by speciesspecific, lipophosphoglycan-mediated midgut attachment. Parasitology 121: 25-33.

Kamhawi S, Ramalho-Ortigão M, Pham VM, Kumar S, Lawyer PG, Turco SJ, Barillas-Mury C, Sacks DL, Valenzuela JG 2004. A role for insect galectins in parasite survival. Cell 119: 329-341.

Kuhls K, Mauricio IL, Pratlong F, Presber W, Schonian G 2005. Analysis of ribosomal DNA internal transcribed spacer sequences of the Leishmania donovani complex. Microbes Infect 7: 1224-1234.

Lainson R 1982. Leishmanial parasites of mammals in relation to human disease. Symp Zool Soc London 50: 137-179.

Lainson R, Rangel EF 2006. Leishmania infantum versus Leishmania chagasi: do not forget the laws of nomenclature: Reply. Mem Inst Oswaldo Cruz 101: 118.

Lainson R Shaw JJ 1979. The role of animals in the epidemiology of South American leishmaniasis. In WHR Lumsden, DA Evans (eds), Biology of the Kinetoplastida, Academic Press, London, New York, San Francisco, vol. 2, p. 1-116.

Lainson R, Shaw JJ 1987. Evolution, classification and geographical distribution. In W Peters, R Killick-Kendrick (eds), The Leishmaniases in Biology and Medicine: Volume I Biology and Epidemiology, Academic Press, London, p. $1-120$.

Oskam L, Pratlong F, Zijlstra EE, Kroon CC, Dedet IP, Kager PA, Schonian G, Ghalib HW, el-Hassan AM, Meredith SE 1998. Biochemical and molecular characterization of Leishmania parasites isolated from an endemic focus in Eastern Sudan. Trans R Soc Trop Med Hyg 92: 120-122.

Quispe-Tintaya KW, Laurent T, Decuypere S, Hide M, Banuls AL, De Doncker S, Rijal S, Canavate C, Campino L, Dujardin JC 2005. Fluorogenic assay for molecular typing of the Leishmania donovani complex: taxonomic and clinical applications. J Infect Dis 192: 685-692.

Rosypal AC, Troy GC, Zajac AM, Duncan Jr. RB, Waki K, Chang KP, Lindsay DS 2003. Emergence of zoonotic canine 
leishmaniasis in the United States: isolation and immunohistochemical detection of Leishmania infantum from foxhounds from Virginia. J Eukaryot Microbiol 50 (Suppl.): 691-693.

Saf'janova VM 1982. Classification of the genus Leishmania Ross. Chapter 11 (in Russian). In The Leishmaniasis. Protozoology, Academy of Sciences, USSR All Union Society of Protozoologists, Lennigrad, Part 7, p. 95-101.

Shaw JJ 1982. Taxonomy of the Genus Leishmania: Traditionlist's View and Modern Concepts. Biochemical Characterization of Leishmania Proceedings of a Workshop held at the Pan American Health Organization, 9-11 December, 1980. Chance MLWalton BC. Geneva Switzerland, UNDP/
WORLD BANK/WHO Special Programme for Research and Training in Tropical Diseases, p. 9-24.

Shaw JJ 2002. New World leishmaniasis: the ecology of leishmaniasis and the diversity of leishmanial species in Central and South America. In J Farrell, World Class Parasites: Leishmania, Kluwer Academic Publishers, Boston, Dordrecht, London, p. 11-31.

Uliana SR, Ishikawa E, Stempliuk VA, de Souza A, Shaw JJ, Floeter-Winter LM 2000. Geographical distribution of neotropical Leishmania of the subgenus Leishmania analysed by ribosomal oligonucleotide probes. Trans $R$ Soc Trop Med Hyg 94: 261-264. 